\title{
A importância da industrialização do xisto brasileiro frente ao cenário energético mundial
}

\author{
The importance of the industrialization of Brazilian \\ shale when faced with the world energy scenario
}

\section{Marilin Mariano dos Santos \\ Dra., Programa de Pós-Graduação em Energia da USP \\ E-mail:marilinsantos@usp.br}

\section{Patricia Helena Lara dos Santos Matai \\ Professora, Dra., Escola Politécnica da USP e Programa de Pós- Graduação em Energia da USP E-mail: pmatai@usp.br}

\section{Resumo}

Esse artigo discute a importância da industrialização do xisto brasileiro, tendo, como base, fatores como: seguridade do sistema de energia nacional, a geopolítica mundial do petróleo, quantidade dos recursos, custo de produção, preço do petróleo, impactos ambientais e as reservas de petróleo nacionais.

O trabalho mostra que a industrialização do xisto sempre surge quando questões como as do peak oil ou da geopolítica do petróleo aparecem como fatores que colocam o preço do barril de petróleo em patamares irreais.

O artigo conclui que, para o caso do Brasil, o xisto pode ser classificado como recurso estratégico, viável economicamente, graças ao sucesso no desenvolvimento da tecnologia de retortagem para extração do óleo, do volume de recursos e do preço do barril de petróleo. O artigo apresenta, também, a conclusão de que o xisto pode ser o fator impulsionador para a formação de um parque tecnológico em São Mateus do Sul, necessário devido à dependência econômica do município em relação à Petrosix.

Palavras-chave: Xisto, energia, industrialização do xisto, petróleo.

\section{Abstract}

This article discusses the importance of the industrialization of Brazilian shale based on factors such as: security of the national energy system security, global oil geopoliticsl, resources available, production costs, oil prices, environmental impacts and the national oil reserves.

The study shows that the industrialization of shale always arises when issues such as peak oil or its geopolitics appear as factors that raise the price of oil to unrealistic levels.

The article concludes that in the Brazilian case, shale oil may be classified as a strategic resource, economically viable, currently in development by the success of the retorting technology for extraction of shale oil and the price of crude oil. The article presents the conclusion that shale may be the driving factor for the formation of a technology park in São Mateus do Sul, due to the city's economic dependence on Petrosix.

Keywords: Shale, energy, shale oil industrialization, crude oil. 


\section{Introdução}

\section{1 o cenário energético mundial e os combustíveis não convencionais}

Amplos debates sobre o fim das reservas de petróleo iniciaram-se, no mundo, em meados da década de 50, quando o geofísico norte-americano Marion King Hubbert previu que, no ano de 1970, os Estados Unidos atingiriam seu pico de produção. Atualmente, as análises sobre a geopolítica do petróleo mostram que a maior parte da oferta de petróleo mundial está localizada em países de forte instabilidade política, como nos países do Golfo Pérsico, na Rússia ou nos países do Golfo da Guiné, pontos que, na última década, têm colocado em discussão a vulnerabilidade do sistema de energia mundial.

A escassez e a geopolítica, somadas a outros fatores, como o fato de que, atualmente, as companhias petrolíferas estatais detêm mais de 1/3 das reservas provadas de petróleo, ficando para as companhias privadas menos de $10 \%$ do controle da produção mundial de óleo e gás, reforçam a baixa competitividade do setor e a sua vulnerabilidade a fatores políticos (Financial Times, 2007).

Especialistas como Robert Hirsch et al. (2005) acreditam que uma das principais ações de mitigação para contornar a vulnerabilidade da oferta de petróleo e, também, para frear uma alta incontrolável do preço do barril é a transição de um sistema mundial de energia pautado no petróleo para um outro mais diversificado. Desse modo, a tendência atual aponta para a substituição do petróleo por fontes não convencionais, sejam elas não renováveis, como o xisto, as areias oleosas, ou renováveis, como a energia solar, eólica e biomassa entre outras. Tal substituição contribuirá para evitar os problemas da exaustão dos recursos, dos conflitos políticos e, também, das questões ambientais.

Mais recentemente, os resultados do USA (2009) mostram que, no futuro, haverá uma queda aguda na produção mundial projetada de petróleo e um aumento na dependência das fontes de combustíveis considerados não convencionais fósseis, como as areias oleosas, petróleo de águas ultra-profundas, óleo de xisto e não convencionais renováveis como os bicombustíveis.

Os USA (2009) projetam, para o ano de 2030, uma produção da ordem de 93,1 milhões de barris de petróleo/dia, número relativamente menor, se comparado com o publicado nos USA em 2007. A produção prevista, para 2030, era de 107,2 milhões de barris/dia. Quanto ao consumo, nos USA (2009) prevêm, para 2030, a produção de 107 milhões de barris de petróleo/ dia de combustíveis líquidos. Nesse cenário, os combustíveis líquidos não convencionais dos tipos não renovável e renovável representarão 12,6 \% da produção, ou seja, 13,4 milhões de barris equivalentes /dia terão de ser produzidos, dos quais $0,2 \%$ serão a partir de xisto.
O cenário anteriormente apresentado coloca a necessidade da utilização das chamadas tecnologias de backstop, como as de produção de óleo a partir de xisto, embora essas tecnologias demandem alto custo e sejam disponibilizadas somente quando há viabilidade econômica, como no caso do primeiro semestre de 2008, quando o preço do barril atingiu valores da ordem de US\$150,00. O valor de mercado do barril de petróleo alcançado nesse período possibilita viabilizar um grande número de tecnologias de backstop. Esse fato não ocorreria no final do segundo semestre do mesmo ano e primeiro trimestre de 2009, quando o valor do barril de petróleo atingiu valores em torno de US\$ 45,00.

Mais recentemente, o problema da escassez, os conflitos políticos e o alto preço do barril de petróleo têm levado países como os Estados Unidos, a Austrália, a Jordânia, a África do Sul e o Marrocos, detentores de recursos de xisto até então considerados estratégicos ou não viáveis economicamente, a retomarem estudos técnicos e econômicos para uma possível produção de óleo de xisto. Outro exemplo refere-se aos projetos canadenses para exploração e produção de óleo a partir das areias oleosas, cujo custo de produção, em 2008, atingiu a marca de US\$ 35,00/barril (Humphries, 2009).

\subsection{História da industrialização do xisto}

O termo xisto é incorretamente aplicado para identificar rochas sedimentares constituídas de finas camadas. A denominação correta é folhelho oleígeno. O material orgânico contido na matriz mineral do xisto é denominado querogênio ou betume, que se decompõe, termicamente, produzindo óleo e gás.

De forma geral, os principais depósitos de xisto situamse em profundidades menores que 1000 metros e estão distribuídos em camadas de espessuras variadas com teores de querogênio, também, variados. Geralmente, o conteúdo de matéria orgânica dos depósitos de xisto oscila de 5 a 25\%, como o da formação Irati em São Mateus do Sul, que possui, em média, 9\% de óleo (Petrobras, 2009).

No que tange à quantidade, os recursos de xisto encontram-se espalhados nos cinco continentes. Os países que se destacam, em quantidade de recursos, são: Canadá, Estônia, China, Rússia, Austrália, Brasil, Estados Unidos, Jordânia, Zaire, Marrocos e Itália. As dimensões desses depósitos abrangem, desde pequenos acúmulos, sem valor econômico algum, até depósitos gigantescos, como o da Formação Green River, no oeste dos Estados Unidos, cujas estimativas indicam a existência de 213 bilhões de toneladas de óleo de xisto in place, ou seja, cerca de 1,5 trilhões de barris (Dyni, 2006).

No Brasil, segundo a Petrobras (2009), as principais áreas com recursos já classificados como reservas localizam-se nos Estados de São Paulo, Paraná, Santa Catarina, Rio Grande do Sul, Mato Grosso do Sul e Goiás. Juntas essa áreas representam 700 milhões de barris de óleo, 9 milhões de toneladas de gás 
liquefeito (GLP), 25 bilhões de metros cúbicos de gás de xisto e 18 milhões de toneladas de enxofre. Tal produção, convertida para barris equivalentes de petróleo (bep), totalizam 889,1 milhões (Petrobras, 2009). Estudos simplificados, realizados nas décadas de 70 e 80 , indicavam que os recursos totais de xisto, no território nacional, totalizam valores próximos a 800 bilhões de barris de óleo (Barros \& Ramos, 1982).

Embora a indústria do xisto seja uma atividade já desenvolvida há várias décadas, ela tem sido, historicamente, relegada a um plano secundário devido às vantagens econômicas, tecnológicas e ambientais apresentadas pelo seu principal concorrente, o petróleo.

Historicamente, o início da utilização do xisto, como um recurso energético, data do final do século XVIII, quando, nos Estados Unidos, cerca de 200 pequenas usinas extraíam óleo de xisto. Em 1859, quando o Coronel Edwin Drake perfurou o primeiro poço de petróleo na Pensilvânia, o xisto foi preterido em prol do petróleo, principalmente porque o custo de extração e beneficiamento desse último ser inferior ao de extração e beneficiamento em relação ao primeiro. Muitas das usinas que processavam xisto acabaram sendo transformadas em refinarias de petróleo (Petrobras, 1982).

No Brasil, desde o final do século XIX, inúmeras tentativas de caráter privado buscaram implantar a industrialização do xisto. Contudo, igualmente a outros países, a exploração e a produção dos recursos de xisto passaram a ter importância no cenário nacional somente no início da Era Vargas, quando, no ano de 1930, as atividades econômicas urbanas foram expandidas devido ao deslocamento do eixo econômico produtivo da agricultura para a indústria. Esse fato acarretou num grande aumento na demanda de energia (Furtado, 1998).

Segundo Marinho Jr (1970), o processo de industrialização nacional levou a um aumento na demanda de petróleo da ordem de 35\% do total de energia demandada em apenas 20 anos. Na época, apenas 3\% do total do petróleo consumido era nacional, fato que, posteriormente, levou a um grande desequilíbrio na balança comercial.

Em 1950, frente à baixa produção nacional de petróleo, às perspectivas do crescimento da demanda e às estimativas significativas dos recursos de xisto nacional, identificadas como próximas a 800 bilhões de barris de óleo, o governo federal criou a Comissão de Industrialização do Xisto Betuminoso (CIXB) com o objetivo principal de estudar as reservas e desenvolver uma tecnologia para processamento do xisto nacional.

Na época, o xisto da Formação Vale do Paraíba foi utilizado no estudo da CIXB. Contudo a apresentação de resultados econômicos insatisfatórios com o xisto do Vale do Paraíba, o sucesso das pesquisas exploratórias na bacia petrolífera do Recôncavo Baiano e o início da operação da Refinaria Landulfo Alves, em Mataripe (BA), estimularam a definição política energética do governo, que privilegiou o petróleo, fato que culminou com a criação da Petrobras em 1953.

Em 1954, a Petrobras criou a Superintendência de Industrialização do Xisto, a Petrosix, cuja meta era a de desenvolver um processo com viabilidade técnica e econômica para processar o xisto nacional. Tal estratégia visava à minimização da importação de combustíveis líquidos.

Vários estudos foram realizados pelos técnicos da Petrosix e os resultados obtidos apontaram para o fato de que o xisto da formação Irati, localizada no Estado do Paraná, era mais adequado do que o do vale do Paraíba, para dar início à industrialização. Em 1967, tendo em vista o estágio da pesquisa do processo de produção e industrialização do xisto, o processo Petrosix ${ }^{\circledR}$, a Petrobrás aprovou a construção de uma usina protótipo (Unidade Protótipo do Iratí - UPI), para industrializar o xisto da Formação Irati, no município de São Mateus do Sul (PR). Os avanços positivos no desenvolvimento do processo
Petrosix $^{\circledR}$ e a primeira crise do petróleo, em 1973, levaram a Petrosix a elaborar, em 1977, um projeto, através do qual seriam construídas vinte retortas para produzir 50.000 barris diários de óleo de xisto a partir do xisto da Formação Irati em São Mateus do Sul.

Em 1983, após a segunda crise do petróleo, a estabilização do preço do petróleo, no mercado internacional, que chegou a valores menores que o custo de produção de óleo a partir de xisto, e as descobertas de petróleo, em terra e mar brasileiros, fizeram com que a Petrobras revisse os seus planos. A decisão foi a construção de uma unidade industrial com apenas uma retorta, com o único objetivo de comprovar a viabilidade tecnológica do processo Petrosix ${ }^{\circledR}$ em escala industrial. O sucesso da tecnologia Petrosix deu-se em 1991.

Atualmente são processadas, diariamente, 7.800 toneladas de xisto, resultando em, aproximadamente, 4.000 barris de óleo combustível, 90 toneladas de nafta industrial, 120 toneladas de gás combustível, 45 toneladas de gás liquefeito, 75 toneladas de enxofre, entre outros produtos e subprodutos (Petrobras, 2009).

Desde a entrada em operação do módulo industrial, a Petrosix vem investindo em melhorias tecnológicas visando a aumentar a eficiência energética global do sistema produtivo de óleo de xisto e valorar os seus rejeitos transformandoos em subprodutos. Os resultados obtidos têm sido bastante satisfatórios, uma vez que a eficiência energética global passou dos 35\%, inicialmente, para próximo de 50\%, nos dias de hoje, resultando em consideráveis reduções nos custos de produção.

Quanto aos rejeitos, os estudos realizados com foco no uso multipurpose do xisto têm demonstrado que: as cinzas de xisto podem ser utilizadas como insumo industrial para produção de cimento; os finos provenientes do tratamento do minério servem como insumo energético com aproveitamento por combustão direta; parte do xisto retortado pode ser utilizada como matéria-prima para a 
indústria de cerâmica vermelha. Mais recentemente, estudos têm demonstrado a utilização da cal xisto e da água amoniacal como insumo para a agricultura.

Além da melhoria no balanço energético global e da valoração dos rejeitos, uma parte dos investimentos tem sido utilizada na prevenção ou mitigação de impactos ambientais afeitos ao processo produtivo (Tonel, 2004).

Atualmente, pode-se constatar que a tecnologia desenvolvida pela Petrosix (que envolve mineração a céu aberto e retortagem de superfície) está plenamente desenvolvida e pode ser classificada como uma tecnologia em estágio comercial.

\subsection{Fatores limitantes para a industrialização}

A análise histórica da industrialização do xisto no Brasil, assim como no mundo, mostra a forte relação com o mercado do petróleo, seu principal concorrente, uma vez que as tecnologias de uso final, para os combustíveis produzidos a partir de ambos, petróleo e xisto, são as mesmas. Contudo, apesar de concorrentes, o petróleo apresenta vantagens sobre o xisto, principalmente, quanto ao custo de produção e às questões ambientais afeitas à exploração e à produção.

O Brasil, diferentemente dos Estados Unidos, detentor do maior depósito de xisto do mundo e com sua produção de petróleo em declínio há pelo menos duas décadas, o Brasil vem aumentando, continuamente, a quantidade de reservas provadas, bem como a produção de óleo segundo os dados publicados pela Petrobras em dezembro de 2008.

As reservas nacionais provadas de óleo, gás natural e líquidos do gás natural somam 14,08 bilhões de barris de óleo equivalentes pelo critério ANP/SPE (Petrobras, 2009 b). Mais recentemente, as novas descobertas de jazidas, na região do pré-sal, cujos valores esperados estão em torno de 50 bilhões de barris de óleo, colocam a grande possibilidade de o Brasil se tornar um grande exportador de petróleo, num futuro não muito distante (JB, 2008).

O estudo de Araújo e Accioly (2006) corrobora a informação publicada pela Petrobras em 2008. Os autores associaram a evolução temporal das reservas provadas brasileiras, em bilhões de barris de óleo equivalente, às fases de exploração e às principais descobertas. Nesse trabalho, os autores apresentam as fases: "terra" (desde a criação da Petrobras até, aproximadamente, 1968), “de águas rasas" (da década de 70, com o desenvolvimento da Bacia de Campos, até 1984) e de "águas profundas" (a partir de 1984 até 2005). Os resultados mostram que o índice de reposição de reservas (IRR) do Brasil vem crescendo e que, no ano de 2005, atingiu o valor de 131,13, segundo os critérios ANP.

Somado ao aumento na quantidade de reservas de óleo e de gás nacionais, o sucesso do programa de bicombustíveis, mais especificamente o do álcool automotivo, substituto do maior uso final de combustíveis líquidos, se por um lado restringe o desenvolvimento da indústria do xisto, por outro coloca o Brasil numa situação bastante confortável no cenário energético mundial, considerando-se somente a quantidade das reservas de petróleo provadas e o sucesso do programa de bicombustíveis.

No que se refere à questão econômica, em 2008, o petróleo produzido, a partir das tecnologias convencionais, teve um custo de produção em torno de US\$ 6,00/barril, para o petróleo produzido no exterior, enquanto que, no Brasil, o custo de produção de um barril de óleo foi, em média, de US\$9,20 (Petrobras, 2009 b). O óleo de xisto produzido com a tecnologia nacional (mineração a céu aberto e retortagem de superfície), por sua vez, apresenta um custo de US\$ 25,00/barril (UNICAMP, 2004).

O alto custo de produção do xisto, quando comparado com o do petróleo, é um dos responsáveis pelo desenvolvimento da indústria do xisto somente em situações de exceção, como é o caso da Estônia, onde o xisto é o único recurso energético disponível, em quantidades economicamente viáveis e o da China, devido à alta demanda de energia. Mais recentemente, devido ao cenário energético mundial, os Estados Unidos deram início a estudos visando ao desenvolvimento da indústria do xisto americano. Os casos de exceção visam, aparentemente, a evitar a importação de energia e, assim a equilibrar a balança comercial e, consequentemente, a evasão de divisas.

Quanto à questão ambiental, no início da década de 80, além de todos os impactos ambientais afeitos à mineração a céu aberto, os grandes problemas eram os rejeitos do processo de extração do óleo da rocha e o tratamento para obtenção dos produtos.

Atualmente, a filosofia da valoração de rejeitos de processo tem levado ao desenvolvimento de novas tecnologias que visam à utilização dos rejeitos do processo de produção de óleo de xisto não apenas para recomposição do solo minerado, mas, também, como matériaprima para outros processos produtivos, minimizando, assim, parte dos impactos gerados e incorporando a prática do uso multipurpose do xisto.

Para o caso do xisto, estudos recentes têm demonstrado a viabilidade técnica da utilização dos três principais rejeitos do processo: os finos de xisto, o xisto retortado e os efluentes líquidos (águas de xisto). A valorização dos finos de xisto pode ocorrer por meio da sua utilização para a geração de eletricidade via caldeiras de leito fluidizado; o xisto retortado pode ser empregado como matéria-prima nas indústrias de cimento e cerâmica; as águas têm usos como corretores de $\mathrm{pH}$ do solo, além do cal-xisto já amplamente utilizado na agricultura.

Além da redução da quantidade de rejeitos que necessitam de destinação final, a valoração dos rejeitos funciona como uma ferramenta para aumentar o valor da relação entre receita e custos.

Apesar do sucesso na valoração dos rejeitos, a questão ambiental ainda é um fator bastante restritivo, isto devido aos altos custos para a mitigação dos impactos causados pelo processo de mineração. 
Outra forte restrição ao desenvolvimento da industrialização do xisto, desvinculada do seu principal concorrente, o petróleo, refere-se à necessidade de grandes áreas para mineração, fato que leva a um conflito entre a população local e a empresa.

No caso do xisto de são Mateus, no início da implantação do projeto, em 1970, a Petrobras adquiriu várias áreas urbanas e rurais no município, visando ao desenvolvimento da indústria do xisto no local, parte das quais foram leiloadas quando da decisão da empresa de abortar a implantação do projeto na sua totalidade, no ano de 1989 (Assunção, 2004, p. 69).

No ano de 2000, a necessidade de abrir novas frentes de lavra para dar continuidade à produção, a Petrobras enfrentou sérios problemas com agricultores, que se sentiam desalojados de suas terras, fato que levou à criação do Movimento dos Afetados pela Petrobras - MAP e causou conflito entre a população rural e urbana. A primeira se sentia lesada pela desapropriação de suas terras e a segunda pela possibilidade de fechamento do complexo industrial devido à falta de matéria-prima (Assunção, 2004, p. 80).

\section{Conclusão}

No que tange à viabilidade técnica e econômica, elas não se colocam como restrições. A viabilidade técnica do processo Petrosix ${ }^{\circledR}$ está comprovada, pois países como Jordânia, Marrocos, Estados Unidos e China têm feito contatos com a Petrobras, visando a parcerias na produção de óleos a partir de xisto, utilizando a tecnologia Petrosix.

Quanto à viabilidade econômica, a escassez do petróleo barato e de fácil obtenção certamente manterá o preço do barril de petróleo em valores vantajosos para a produção de óleo a partir de xisto, uma vez que os custos para exploração e produção dos recursos de petróleo disponíveis são cada vez mais elevados por serem de mais difícil exploração e a transição de uma matriz energética pautada em petróleo para outra é uma tarefa de longo prazo.

Contudo a análise da história da industrialização do xisto no Brasil e a análise das restrições discutidas indicam que o desenvolvimento da industrialização do xisto no Brasil deve observar a diversificação da matriz energética, cuja participação dos recursos energéticos ambientalmente mais amigáveis é bastante expressiva. Outro fator que deve ser levado em consideração é a quantidade dos recursos energéticos nacionais, principalmente do petróleo, e a dependência econômica do município de São Mateus do Sul em relação a Petrosix. Caso essa industrialização ocorra, ela deve se dar, principalmente, pelo uso da parcela não energética do xisto, ou seja, pelo uso multipurpose do xisto, o que, não só auxiliará a aumentar as receitas da unidade de produção de óleo, mas, também, alavancará um pólo de desenvolvimento regional. Os benefícios englobam, não somente os aspectos econômicos, como a geração de empregos e o aumento das receitas municipais, mas, também, irá melhorar ainfra-estrutura local.

O fato de a Secretaria de Planejamento do Estado do Paraná criar, em 1997, um grupo de trabalho para apresentar as diversas possibilidades de utilização dos rejeitos do xisto demonstra a sua viabilidade enquanto fonte de energia. Assim, estimulou-se o desenvolvimento do Parque industrial do Xisto e criou-se as Incubadoras Tecnológicas de São Mateus do Sul, cujo objetivo principal era incentivar a criação de novas empresas que utilizassem os rejeitos do xisto, visando ao desenvolvimento de novos produtos (Paraná 1998, p. 3).

\section{Referências bibliográficas}

ARAúJO, J. A. M., ACCIOlY, P. C. V. Estimativa de reservas no $E \& P$ - Brasil. Rio de Janeiro: Boletim técnico da Produção de Petróleo, v. 1, n. 1, junho de 2006, p. 39-49. Disponível em: http://www2.petrobras. com.br/portal/frame.asp?pagina=/ tecnologia/port/publicacoes_btecnicos. asp\&lang=pt\&area=tecnologia. Acesso em 05/07/2009.

ASSUNÇÃO, H.K. Parque industrial do xisto: estratégia de desenvolvimento local para São Mateus do Sul-PR. Florianópolis: Departamento de Geociências do Centro de Filosofia e Ciências Humanas da Universidade Federal de Santa Catarina, 2004. 150p. (Dissertação de Mestrado em Geografia).

BARROS, R.P., RAMOS, L.R.A. Um modelo de crescimento para a indústria de xisto. Rio de Janeiro: IPEA, 1982. n. $4, \mathrm{p}, 57$. (Documento preliminar do grupo de energia - texto para discussão).

DYNI, J. R. Geology and resources of some world oil-shale deposits. Oil Shale Journal, v. 20, n. 3, p. 193-252, 2003. Estonian Academy Publishers. Disponível em http://www.kirj.ee/ oilshale/vol_20_3.html>. Acesso em outubro de 2008.

Energy Information Administration. International. Energy Outlook 2009. U.S. Department of Energy. Office of Integrated Analysis and Forecasting DOE/EIA-0484(2009). Washington. EUA May 2009. Disponível em www. eia.doe.gov/oiaf/ieo/index.html. Acesso em julho de 2009.

FINANCIAL TIMES. The new seven sisters: oil and gas giant. By Carola Hoyos. Mar 11 2007. Disponível em: http://www.ft.com/cms/s/2/471ae1b8d001-11db-94cb-000b5df10621.html Acesso em 04/10/2007.

FURTADO, M. B. Síntese da economia brasileira. (6. ed.). Rio de Janeiro: LTC, 1998.

HIRSCH, R. L., BEZDEK, R., WENDLING, R. Peaking of world oil production: impacts, mitigation, \& risk management. Washington: DOE, 2005. p.91. Disponível em: <http://www.netl.doe. gov/publications/others/pdf/oil_peaking_ netl.pdf.> Acesso em: 15/07/2008.

HUMPHRIES, M. North american oil sands: history of development, prospects for the future congressional research service. Resources, Science, and Industry Division. Ca. 2008. Disponível em http:// fas.org/sgp/crs/misc/RL34258.pdf. Acesso em 05/07/2009.

ITS Incubadora Tecnológica de São Mateus do Sul. A oportunidade de incubar sua empresa e desenvolver seu produto com a Petrobras. São Mateus do Sul: Editora da Petrobras, 1998. 
JB - JORNAL DO BRASIL. Reservas do présal podem chegar a 50 bilhões de barris. Jornal do Brasil on line, Agencia Brasil. 07.11.2008; 16h17. Disponível em http:// jbonline.terra.com.br/extra/2008/11/07/ e071120788.html Acesso em 05/07/2009.

MARINHO JR, I. P. Petróleo: soberania e desenvolvimento. Rio de Janeiro: Bloch, 1970.

PARANÁ. Pólo tecnológico $\boldsymbol{e}$ industrial do xisto. Secretaria de Planejamento do Paraná, dez. 1998. p 158. (Relatório Interno).

PETROBRAS http://www2.petrobras.com. $\mathrm{br} / \mathrm{minisite/refinarias/petrosix/portu-}$ gues/oxisto/oxisto_reservas.asp Acesso em 02/07/2009. (b) Relações com os investidores/Informações operacionais http://www2.petrobras. com.br/portal/frame_ri.asp?pagina=/ri/port/index.asp\&lang=pt\&area=ri Acesso em 01/07/2009.

. A industrialização do Xisto. Rio de Janeiro: Serviço de Comunicação Social, 1982. p 80. (Cadernos Petrobrás, n.6).

TONEL, G. Processamento de xisto. Santa Maria: Universidade Federal de Santa Maria, 2004. 33f. (Monografia - Trabalho de Conclusão da Disciplina de Processos Químicos Industriais). Disponível em: <http://br.geocities.com/giovanitonel/chemical_eng_files/ process_xisto.htm>. Acesso em: 10/09/2008.

UNICAMP. A Petrobras no Paraná negocia contratos para exportar tecnologia para países da Ásia. Unicamp: Núcleo de Excelência em Engenharia de Petróleo. Biblioteca Virtual de Engenharia do Petróleo. Boletim BE52 de 16.09.2004 . Disponível em http://www. dep.fem.unicamp.br/boletim/BE52/artigo.htm Acesso em 05/07/2009.

Artigo recebido em 18/09/2009 e aprovado em 20/03/2010.

\section{Maneiras para divulgar suas pesquisas: \\ - Contar para o colega de sala.}

- Deixar uma cópia na biblioteca de sua Universidade.

\section{Mas a melhor maneira de divulgar suas idéias é publicá-las na REM:}

- Indexada: no Scielo, ISI, Scopus, Ebsco, Geosciences

- Periodicidade Trimestral: sem atraso

- Editores e Conselho Editorial de várias Universidades

- Mais de $\mathbf{4 0 0}$ pesquisadores cadastrados como avaliadores ad hoc

- Financiada pelo CNPq e Fapemig

- Apoiada pela Vale, Gaustec, INOX, Petrobras, Geosol, Votorantim, Georadar, Anglo American, Samarco

- A primeira revista do setor mínero-metalúrgico da América do Sul

- A primeira revista do setor mineral a obter ISO 9001:2008

-A REM faz parte do Programa "Open Access". 